\title{
El hombre aumentado, ¿última fase de la antropogenia neoliberal? ${ }^{1}$
}

\author{
Augmented man: final stage of the neoliberal \\ anthropogenesis?
}

JULIEN CANAVERA² (Universidad de Zaragoza)

Artículo recibido: 16 de febrero de 2021

Solicitud de revisión: 2 de abril de 2021

Artículo aceptado: 25 de noviembre de 2021

Canavera, Julien (2022). El hombre aumentado, ¿última fase de la antropogenia neoliberal? Recerca. Revista de Pensament i Análisi, 27(1), pp. 1-24.

doi: http://dx.doi.org/10.6035/recerca.5772

\section{Resumen}

El propósito del presente artículo es mostrar en qué medida el proyecto transhumanista de optimización humana, cuyo contenido manifiesto incide ante todo en la ambición, a priori legítima, de perfeccionarse a uno mismo, entronca en realidad - a la vez que prolonga- con el programa neoliberal de dar a luz al hombre nuevo, más capacitado para adaptarse al entorno competitivo, que el capitalismo postfordista viene construyendo desde hace más de cuatro décadas.

Palabras clave: transhumanismo, tecnociencia, neoliberalismo, capitalismo, sujeto.

\begin{abstract}
The purpose of this article is to show to what extent the transhumanist project of human optimisation, which manifest content insists primarily with the a priori legitimate ambition to perfect oneself, actually connects with - and prolongs - the neoliberal programme of giving birth to the "new man", more able to adapt to the competitive environment that post-fordist capitalism has been constructing for more than four decades.

Key Words: transhumanism, technoscience, neoliberalism, capitalism, subject.

\footnotetext{
${ }^{1}$ Este trabajo ha sido elaborado en el marco del proyecto de investigación «Racionalidad económica, ecología política y globalización: hacia una nueva racionalidad cosmopolita» (PID2019-109252RB-I00), financiado por el Ministerio de Educación e Innovación de España.

${ }^{2}$ canavera.julien@gmail.com
} 


\section{INTRODUCCIÓN}

Recientemente, el célebre cofundador de una startup de neurotecnología estadounidense, especializada en el desarrollo de interfaces cerebrocomputadora, ha declarado haber logrado implantar un microprocesador en el cerebro de un simio «para que use videojuego con la mente» (EFE, 2021); antes de añadir acto seguido que su empresa está lista para iniciar en breve los primeros ensayos en humanos. Si la susodicha empresa deja constancia de que una de las primeras misiones asignadas a dicho implante cerebral es la -terapéutica- de devolver su motricidad a personas aquejadas de parálisis, no por ello descarta la posibilidad, en un futuro próximo, de extender su uso a fines de optimización para, por ejemplo, permitir una suerte de comunicación telepática entre humanos, o incluso para alcanzar la simbiosis entre inteligencias humana y artificial. Asimismo, si no es de sorprender que, debido a semejantes avances biotecnológicos, crezca el número de adeptos 3 (filósofos, científicos, políticos, economistas, artistas, etc.) al proyecto transhumanista de optimización humana y ello a medida que la tecnociencia le gana terreno a la ciencia-ficción y que, según parece, se acerca con celeridad el momento en que el hombre podrá hacer alarde de nuevas aptitudes. En cambio, nos resulta harto llamativo, aunque sean más bien pocos quienes reparen en ello, no solo la afinidad, sino más profundamente la continuidad ideológica que se da entre el human enhancement (según su expresión inglesa) y el llamamiento neoliberal a que el hombre se convierta en el empresario de sí mismo. En efecto, bajo el manto de promesas aparentemente seductoras (pues, ¿quién a priori no quiere gozar de mejor salud, ser más atractivo o tener mayor éxito en la vida?), nos ha parecido que el proyecto transhumanista no hace en última instancia otra cosa que no sea llevar a un nivel, hasta entonces insospechado, la ambición postfordista de enrolar a los individuos en el deseo-amo del capital. Una extensión del dominio de la lucha que, como trataremos de mostrar a continuación, pasa por la colonización tecnocientífica y biomédica de los cuerpos productivos.

Para ello, recordaremos primero cómo el neoliberalismo ha venido implementando una gubernamentalidad empresarial que insta a los individuos a dar constantemente lo mejor de sí. Luego veremos en qué medida este llamamiento a la autosuperación incesante se agudiza con la apuesta transhumanista por la tecnociencia como herramienta de biomejoramiento hu-

\footnotetext{
${ }^{3}$ Cuando no de «pararreligiosos» (Damour, 2017: 54).
} 
mano. Por último, se evidenciará cuánto el proyecto de human enhancement culmina la lógica de supeditación total del hombre (en alma y cuerpo) al ciclo de valorización del capital.

\section{LA GUBERNAMENTALIDAD, PIEDRA ANGULAR DEL CAPITA- LISMO POSTFORDISTA}

Si bien las sociedades modernas, tal y como dice Marx al principio de $E l$ capital, son todas aquellas «en las que domina el modo de producción capitalista» (2008: I, 43), no quita que semejante modo de producción, al igual que las estructuras sociales fundamentales por las que se caracteriza, ${ }^{4}$ han sido objeto de actualizaciones concretas a lo largo de la historia. Así, conforme a las puntualizaciones acometidas —en particular, aunque no solopor la escuela de la regulación, nos interesa subrayar cuán necesario resulta proceder a una «periodización histórica» (Boyer, 1986) del régimen de acumulación capitalista para no caer en simplificaciones a la hora de analizar sus implicaciones económicas, sociales, políticas y subjetivas, pues nunca ha existido algo así como el capitalismo, en estado puro; antes bien, lo que se ha dado son distintas configuraciones históricas de sus estructuras fundamentales, de modo que resulta mucho más conveniente hablar de capitalismos, en plural. Siguiendo asimismo a Lordon (2010b), uno de los más significativos representantes actuales de la corriente heterodoxa precitada, se pueden rastrear las tres grandes actualizaciones históricas que ha conocido el capitalismo a lo largo de los últimos dos siglos: regímenes de acumulación decimonónico, fordista y neoliberal.

Sentado esto, no cabe duda de que el neoliberal constituye el régimen de acumulación característico de la actualidad. Ahora bien, si resulta importante levantar acta de que «no vivimos simplemente en una economía capitalista sino en la sociedad capitalista» (Lordon, 2010a: 114), es porque se puede identificar el modo de funcionamiento del capitalismo actual con el prolongamiento - cuando no el acabamiento-de lo que Marx, en El capital, denomina la «subsunción real del trabajo en el capital», entendiendo por ello el proceso de extracción de sobrevalor, propio de la segunda época de la

\footnotetext{
${ }^{4}$ En cuyo centro se halla la relación laboral (concebida como «el efecto de una doble desposesión/separación de los productores con las herramientas de la producción y los productos de la producción») y, con ella, la correspondiente y obligada «mercantilización de la fuerza de trabajo», encubierta por las «formas jurídicas del libre contrato» (Lordon, 2010b: 128).
} 
historia de la acumulación capitalista, en virtud del cual son movilizados - en aras de incrementar la productividad del trabajo y, por consiguiente, el sobretrabajo (del que el capital extrae la plusvalía) - no solo la actividad productiva como tal, realizada en el seno de la empresa, sino más generalmente el conjunto de las esferas sociales y de las actividades correspondientes. En este sentido, Marx no hace otra cosa que no sea describir el modo de funcionamiento capitalista en la forma de un régimen de movilización y supeditación total (de la ciencia, la tecnología, la cultura, la política, la vida social e incluso la subjetividad) al ciclo del capital, que encuentra asimismo en su configuración neoliberal un nuevo prolongamiento, pues el capitalismo postfordista, al tratar de inmiscuirse en lo más hondo de las subjetividades deseantes, no tiene otro cometido que el de «reconfigurar los deseos individuales con el propósito de alinearlos bajo el deseo-amo del capital» (Lordon, 2013: 94) o, si se prefiere, de orquestar un enrolamiento total de las subjetividades.

En otras palabras, lo característico del capitalismo neoliberal es que no se agota, como tienen a bien señalar Steger y Roy (2011), en un conjunto de medidas y políticas económicas, ${ }^{5}$ ni tampoco en una ideología abiertamente mercantilista o economicista; además de ello, conlleva el despliegue - lo veníamos diciendo- de una nueva forma de gubernamentalidad, en el sentido que Foucault (2007) otorga a este término, o, si se prefiere, de razón, como arguyen Laval y Dardot (2013) en la estela del filósofo francés. Repararemos primero en que por «gubernamentalidad» se refiere aquí al arte de gobernar, es decir, al conjunto de prácticas y técnicas que emplean aquellos individuos que, independientemente de su pertenencia al gobierno (como institución), tratan de orientar la acción de los demás en la dirección oportuna, remontándose para ello hasta las disposiciones o resortes afectivos que hacen hacer. En efecto, recordaremos con Foucault (2007) que el gobierno (como actividad) se distingue de la simple dominación, del mero enfrentamiento cuerpo a cuerpo, en la medida en que «no pretende anular la iniciativa de los gobernados —es decir, su práctica de la libertad-imponiéndole un estándar, sino emplearla a su favor» (Vázquez, 2005: 75). Por esto es por lo que la libertad de los gobernados, recuerda Vázquez, se halla necesariamente presupuesta por el gobierno, pues el gobierno como actividad, lejos de coincidir con un ejercicio meramente negativo del poder (coacción), está

\footnotetext{
${ }^{5}$ Que nuestros autores resumen con la «Fórmula D-L-P»: desregulación de la economía (D), liberalización de la industria y del comercio (L), privatización de las empresas estatales (P) (Steger y Roy, 2011: 34).
} 
grávido al contrario de una innegable positividad por cuanto trata de fomentar la acción de los gobernados (incentivación), de tal suerte que estos últimos se imaginen obrar conforme a su deseo y libre decreto (como diría el Spinoza del Tratado político).

[Gobernar] es conducir las conductas de una población, de una multiplicidad que es preciso cuidar como un pastor lo hace con su rebaño para maximizar su potencial y orientar su libertad. Es, por tanto, considerar y moldear sus deseos, sus modos de hacer y de pensar, sus costumbres, sus miedos, sus disposiciones, su medio (Comité Invisible, 2015: 71).

Ahora bien - he aquí el segundo punto en el que queríamos incidir-, resulta que el arte de gobernar, como bien apunta Foucault, no solo consiste en «conducir las conductas» de los demás; también implica una determinada forma de conducir la conducta propia. De este modo, queda patente que la del gobierno es también, y en último análisis, la cuestión del autogobierno, pues siguiendo la interpretación que nos brinda Vázquez (2005: 80), así como existen «técnicas heteroformativas» de la subjetividad (a las que Foucault denomina «tecnologías de gobierno»), asimismo se dan «técnicas autoformativas» (las llamadas «tecnologías del yo») que, si bien pueden dar pábulo a una contestación del gobierno como actividad, ${ }^{6}$ no por ello dejan de quedar a merced de una amenaza latente: la de entremezclarse con las primeras y de acabar interiorizándose en las subjetividades hasta el punto de determinarlas a lo que Spinoza (1986: 95) llama el obsequium (literalmente, la tendencia a seguir, la «dependencia del sendero»). Pues bien, si queda claro que están imbuidas de cierta ambivalencia, resta empero que dichas «técnicas del yo» no están sino llamadas, en la era del neoliberalismo, a «[tomar] el relevo de las estrategias de gobierno» (Vázquez, 2005: 83).

\section{LA EMPRESA COMO MODELO DE AUTOGOBIERNO}

En efecto, una de las consecuencias - a todas luces cruciales- del acabamiento neoliberal del proceso de «subsunción real del trabajo en el capital» es que la subjetividad se convierte en el campo de batalla político por antonomasia, siendo asimismo el deber de «la política neoliberal» el de

\footnotetext{
${ }^{6}$ Puesto que la «inducción institucional del deseo» (Lordon, 2010a: 123) siempre corre el peligro de ser percibida como una coacción y de convertirse, por tanto, en objeto de rechazo.
} 
«cambiar al hombre mismo» (Laval y Dardot, 2013: 87). Pues de la ambición - lo veníamos diciendo- de subordinarlo todo a la racionalidad económica, empezando por la propia racionalidad política, que se ve asimismo supeditada al imperativo de «gobernar no solo para el mercado, sino también con arreglo a lo que requiere la lógica mercantil» (Lagasnerie, 2012: 54), se sigue - a modo de consecuencia casi lógica o natural - el proyecto de supervisar y pilotar a su vez el proceso de subjetivación de los agentes llamados a operar en la sociedad de mercado. Más concretamente, de lo que se trata es de conducir sus conductas de tal modo que acaben interiorizando el de la entidad capitalista como el modelo mismo del autogobierno: "Empresa" es también el nombre que se debe dar al gobierno de sí en la era neoliberal» (Laval y Dardot, 2013: 333). Así es como los hombres, en la sociedad postfordista, están llamados a vivir y a aprehenderse a sí mismos como auténticas unidades de producción que se hallan constantemente en relación de competencia con otras unidades dentro de un entorno de carácter marcadamente agonístico.

Ahora bien, si los teóricos del neoliberalismo, especialmente von Mises, Hayek, Eucken o Röpke, están de acuerdo, pese a las diferencias que los separan, en que hace falta reconfigurar al hombre, es porque no ven en él a un competidor nato. En efecto, uno de los rasgos distintivos del neoliberalismo radica en su ruptura con la ontología naturalista propia del liberalismo clásico de un Smith o un Ricardo y, por ende, con el dogmático laissez-faire en el que él mismo se degrada a consecuencia de la revolución marginalista acometida por Jevons, Menger y Walras, pues ni el mercado ni el homo oeconomicus son datos originarios (que operan tanto mejor cuanto más se minimiza la intervención estatal); antes bien, ambos requieren ser fabricados, lo que implica todo un intervencionismo liberal (cuyos objetivos no se confunden, empero, con la prosecución de fines sociales, como en el caso del Estado keynesiano). En otras palabras, así como el mercado no puede ser funcional a defecto de un marco jurídico-político, ${ }^{7}$ de un código de circulación, debidamente instaurado, que posibilite la coordinación - aunque sea in extremis - de la multitud de procesos (esto es, de interacciones socioeconómicas entre agentes) que se dan en su seno, asimismo le resulta harto difícil, cuando no imposible, al individuo operar exitosamente en semejante entorno competitivo sin haber sido previamente educado en valores (adaptabilidad, empleabilidad, rendimiento, crecimiento, sentido del riesgo y de la autorresponsabilidad, etc.).

\footnotetext{
${ }^{7} \mathrm{Y}$ también material (infraestructuras y redes de transporte, comunicación, saneamiento, etc.).
} 
Por esto es por lo que la inserción exitosa del individuo en el tejido altamente competitivo de la sociedad de mercado en su versión neoliberal, más que en el paradigma de la disciplina (como pudo ser el caso en la era fordista), sitúa antes bien su condición de posibilidad en el de la flexibilización (Fraser, 2003). En pocas palabras, de lo que se trata no es sino de llevar al individuo a incorporar una serie de valores, discursos y prácticas que afiancen en él el sentido de la adaptación, única forma de sobrevivir en un entorno evolutivo, cambiante e incierto donde el fracaso solo puede ser achacado a la responsabilidad individual. Es, pues, de este nuevo imperativo — «es preciso adaptarse» (Stiegler, 2019) - de donde se deriva el llamamiento neoliberal a convertirse en el empresario de sí mismo o, si se prefiere la terminología acuñada por Gary Becker (1983), a aprehenderse a uno mismo como un capital humano que cada cual tiene la imperiosa responsabilidad de valorizar constantemente y ello en todos los medios (personal, conyugal, amistoso, laboral, etc.) en los que se despliega su existencia. Si Lordon, por su parte, llega incluso a parangonar el proceso de subjetivación neoliberal con un «proyecto de colonización integral de las almas» (2010b: 142), es porque la ambición de rehacer al hombre conlleva en último análisis una reestructuración interna de la subjetividad que nuestro autor identifica con una «posesión de las interioridades» (2010b: 142).

En resumidas cuentas, el proyecto neoliberal de convertir al hombre no tanto en un homo oeconomicus, ceñido como tal a la operación pasiva del cálculo maximizador, cuanto en un homo agens (según la expresión acuñada por Ludwig von Mises), es decir, en un agente cuya adaptabilidad y reactividad -incesantemente fomentada por el entorno competitivo en el que se despliega su existencia- le predispone a convertir toda incertidumbre en una oportunidad (de valorizarse como capital humano), tal proyecto - decíamos - se enmarca en último análisis en lo que conviene llamar una antropogenia, una reconfiguración antropológica total (itotalitaria?) que, dicho sea de paso, nada tiene que envidiar, pese a las mofas de las que fue objeto, al proyecto soviético de engendrar al hombre nuevo. Henos aquí, pues, con la antropogenia neoliberal - cuyas directrices ya se estaban fraguando en el marco del Coloquio Walter Lippmann (Laval y Dardot, 2013: 88) —: se trata de mejorar al hombre -y, a tal fin, de hacerlo partícipe de su mejora-para que, de este modo, sea capaz de adaptarse a la eclosión de esta ciudad libre (Lippmann, 2011) donde la lógica del mercado y su núcleo duro, el principio de competencia, están camino de afianzar su dominio hegemónico sobre la totalidad de las esferas sociales. 
Llegados a este punto, nos interesa subrayar empero que el proyecto de engendrar al hombre nuevo se remonta (al menos) a la Ilustración y se apoya, entre otras cosas, en la nueva concepción antropológica estructurada en torno al ideal liberal de autonomía: el hombre, concebido como subjectum (o sujeto soberano), es quien elige ahora qué ley debe darse a sí mismo para orientarse en la existencia. Ahora bien, de esta concepción del hombre como sujeto-legislador se deriva, a su vez, la -concomitante- del hombre como ser moldeador de sí mismo, de la que se hacen eco los diversos proyectos de transformación antropológica y política que han venido floreciendo en Occidente durante los últimos dos siglos, especialmente el marxismo, por un lado, y los programas neoliberal y transhumanista, por el otro. El ideal liberal de autonomía trae efectivamente consigo una promesa de emancipación a la que los proyectos transformadores precitados han tratado (o tratan) de dar salida mediante la elaboración de una nueva humanidad. Así, se dirá de las propuestas marxista, neoliberal y transhumanista que comparten la idea de crear a un hombre nuevo y también que todas - aunque especialmente la marxista y la transhumanista - se las tienen que ver con el temor que semejante revolución antropológica tiende a infundir en el imaginario colectivo, al evocar «las experiencias totalitarias, los programas de biotecnología y las criaturas salidas de las obras de ciencia-ficción» (DayanHerzbrun, 2005: 96).

Pero, una vez señalados algunos de sus puntos comunes, creemos que un estudio más pormenorizado de estas diferentes propuestas revelaría cuán discutible es considerarlas a todas por igual. De hecho, nos interesa señalar al menos un aspecto en el que los diversos proyectos decimonónicos de transformación antropológica y política, en particular el marxismo, difieren de las propuestas neoliberal o transhumanista: es la idea de que no se puede mejorar a los hombres, seres fundamentalmente relacionales, sin «cambiar [previamente] las instituciones, leyes, gobiernos, centros de trabajo, viviendas, escuelas y demás [estructuras sociales]» (Winner, 2002: 36), en las que despliegan su existencia. En definitiva, se trata de dos concepciones radicalmente distintas de la subjetividad y del perfeccionamiento humano: mientras que el marxismo concibe al ser humano como un sujeto relacional (subditum) cuyo mejoramiento depende de la realización de un proyecto de transformación social, tanto el neoliberalismo como el transhumanismo se empeñan en reconducir acríticamente la figura del sujeto constituyente (subjectum), cuyo perfeccionamiento es asunto de responsabilidad individual y buena voluntad. 
Para proseguir con dicha consigna de autosuperación formulada en clave individualista, recordaremos que el propio neoliberalismo no escatima medios para lograr que los hombres den individualmente lo mejor de sí. De hecho, los métodos formativos procedentes del management son parte de los recursos a los que apela la gubernamentalidad neoliberal para, a imagen del coaching, acostumbrar a los individuos a «transformar una presión exógena en una motivación endógena» (Lordon, 2010a: 128). Ahora bien, semejante consigna de autosuperación cobra ciertamente una dimensión inaudita a la luz de las innovaciones tecnocientíficas y biomédicas de la ciencia en acción (Latour, 1992), así como de las promesas correspondientes de optimización del ser humano que estas encierran, pues, a día de hoy, la tecnociencia está en condiciones de brindarle al hombre la posibilidad real, si así lo desea, de mejorarse directamente a sí mismo mediante el injerto de implantes, prótesis y otros dispositivos biotecnológicos capaces de incrementar sus facultades (mentales, sensoriales, físicas y emocionales), más allá de lo que consideramos ser sus límites naturales. Tal es, de hecho, la apuesta del transhumanismo, ${ }^{8}$ este principal codificador ideológico del giro biotecnológico del capitalismo actual, cuyo contenido manifiesto - el de optimizar al ser humano- entronca plenamente, a la vez que lo agudiza, con el llamamiento neoliberal a valorizar constantemente este capital humano que somos, pues de la llamada convergencia de las NBIC $^{9}$ se sigue asimismo la posibilidad de llevar la cuestión del autogobierno a un umbral, hasta entonces insospechado, por cuanto se le brinda al hombre la oportunidad de rehacerse a sí mismo y ello desde la materialidad biológica misma de su cuerpo.

\section{LA ANTROPOGENIA NEOLIBERAL BAJO EL PRISMA DE LA TECNOCIENCIA}

Si semejante reseteo de lo humano resulta hoy materialmente posible, es porque la exploración científica del hombre, como dice Hottois (2006: 32),

\footnotetext{
${ }^{8}$ Movimiento intelectual y cultural, nacido en los años 1980 en la Silicon Valley, actual bastión del tecnocapitalismo encarnado por las GAFAM (Google, Apple, Facebook, Amazon y Microsoft), que tiene como objetivo mejorar las aptitudes del ser humano, recurriendo para ello a las innovaciones tecnocientíficas y biomédicas desarrolladas por la ciencia contemporánea. El transhumanismo retoma en este sentido un proyecto de perfeccionamiento humano cuyas premisas ya se pueden rastrear en los escritos de Julian Huxley, el hermano de Aldous, o incluso en la obra de Francis Galton, el primo de Darwin.

${ }^{9}$ Campo científico interdisciplinar en el cruce de las nanotecnologías ( $\mathrm{N}$ ), las biotecnologías (B), la informática (I) y las ciencias cognitivas (C).
} 
de «exclusivamente simbólica» - es decir, de «asunto de discurso, de interpretación hermenéutica y de representación»-, ha pasado a ser «cada vez más tecno-física, experimental y operativa». Ahora bien, este nuevo rumbo de la exploración humana, en virtud del cual se desvela la «inmanencia del sujeto en el objeto que el sujeto estudia y transforma» (Lyotard, 1986: 32), no se debe sino - lo veníamos diciendo- al auge y desarrollo de la tecnociencia durante las últimas décadas del siglo XX. ${ }^{10}$ Este es, en pocas palabras, el resultado de la radical inversión, iniciada en los albores de la modernidad y consumada en la era contemporánea, del vínculo jerárquico que unía los dos términos del binomio teoría/técnica, y que se caracterizaba, como de ello da perfectamente cuenta la tradición de la ciencia aristotélico-tomista, por primar la theōría y su gratuidad sobre una téchne entonces adosada a la mera observación empírica y ceñida al ámbito de lo fabril. Con el advenimiento de la tecnociencia, ya no se trata tanto de producir un saber puramente contemplativo o «logoteórico», es decir, «un discurso racional articulado que contempla o refleja la estructura racional de lo real» (Hottois, 1991: 13), sino al contrario, la cuestión estriba de ahora en adelante en conceptualizar lo real como algo procesual, interactivo y, por tanto, operable, pues de lo que se trata es de saber para hacer, transformar, manipular.

Así es como, del descubrimiento moderno del carácter operativo del conocimiento científico ${ }^{11}$ (resumido en la fórmula baconiana «saber es poder») al nacimiento de la tecnociencia misma, se presencia el despliegue de una ciencia que, paulatinamente, pone fin, con una mano, a la «primacía tradicional de la teoría» (Hottois, 1991: 11) y acaba consagrando, con la otra, el «ideal intervencionista de la técnica» (del que, dicho sea de paso, La Nueva Atlántida nos brindaba ya la fórmula: «hacer todo lo que se puede hacer»). El de «tecnociencia», finalmente, no es sino el nombre - recala Hot-

\footnotetext{
${ }^{10}$ Y cuyo paradigma sitúa Hottois en el Proyecto Genoma Humano, iniciado en los años 1990.

${ }^{11}$ Son los modernos, empezando por Bacon y Descartes, quienes se conciencian de que es el conocimiento teórico de la(s) causa(s) eficiente(s) de tal o cual efecto físico lo que posibilita la posterior intervención técnica sobre dicha(s) causa(s) para producir, modificar o suprimir el efecto en cuestión. En este sentido, la ciencia es objeto de un doble deslizamiento que equivale a un proceso de convergencia: así como el saber, de gratuito, pasa a ser útil en la precisa medida en que da lugar a aplicaciones técnicas, asimismo la técnica, de meramente empírica, pasa a tener un fundamento teórico en virtud del cual incrementa su eficacia operativa (que la actividad productiva —el trabajo — trata de incorporar, cuanto sea posible, en su quehacer de transformación de la naturaleza para facilitar la reproducción material y biológica del hombre). De este proceso de convergencia se deriva finalmente un fenómeno de retroalimentación creciente entre teoría y técnica a raíz del cual no hay descubrimiento teórico-científico que no acabe plasmándose en una aplicación técnica, ni tampoco avance técnico que no termine abriendo nuevas perspectivas teóricas.
} 
tois- de «la transformación de una ciencia que apunta a la representación [de lo real] en una ciencia activa, operativa», cuya labor teórica se ciñe exclusivamente, de ahora en adelante, a «las interacciones del científico con lo real» (2006: 24). En este sentido no le falta razón a Lyotard cuando, al hacer hincapié en la existencia dominante de la ciencia como tecnociencia, tiene a bien definirla como «la subordinación masiva de los enunciados cognoscitivos a la finalidad de la mejor performance posible» (1986: 19). Y es que, al poner un énfasis creciente en la ciencia aplicada, a expensas de la ciencia pura, se duda cada vez menos en afirmar, ya no tanto el entrelazamiento, cuanto la primacía del polo técnico sobre el polo teórico-científico. Así es como «la ciencia se [convierte] en un medio de la técnica» (Ellul, 2008: 17) y corre asimismo el riesgo de sucumbir, si es que no lo hace ya, a la dictadura de los medios, es decir, al imperativo tecnológico de «hacer todo lo que se puede hacer». ${ }^{12}$

En resumidas cuentas, diríase, para retomar una fórmula de Don Ihde, que la «tecnología-conducida-por-la-ciencia» deja paso, en la era tecnocientífica, a la «ciencia-conducida-por-la-tecnología» (citado en Hottois, 2006: 27); lo cual implica - tal y como veníamos sugiriendo- un proceso de instrumentalización y subordinación al quehacer tecnológico tanto de la finalidad cognoscitiva como de los valores epistémicos asociados (verdad, objetividad, desinterés, universalidad, etc.), que desemboca, en último análisis, en una forma radicalmente distinta de aprehender al sujeto y al objeto de la ciencia, pero también, más profundamente, en la formulación de nuevos presupuestos ontológicos. En efecto, ya no nos las tenemos que ver con un sujeto contemplativo, que se limita a ver y a hablar de la esencia de un objeto inoperable; antes bien, de lo que se trata ahora es de un sujeto manipulador que tiene a mano un objeto plástico acerca del que se pregunta qué puede hacer con él, pues una de las consecuencias que se derivan del desarrollo de la capacidad manipuladora y transformadora de la ciencia vuelta tecnociencia es, como bien señala Günter Ropohl, que la primera pregunta kantiana «¿Qué puedo saber?» se prolonga automáticamente en la pregunta «QQué puedo hacer o fabricar?» (citado en Hottois, 1991: 28-29). En este sentido, recalca Hottois, el paradigma ontológico dentro del que se enmarca la actividad tecnocientífica del sujeto manipulador, que hace, deshace y rehace a voluntad la materia (ya sea física, viva o pensante), es el del «mate-

${ }^{12}$ Con todas las implicaciones (bio)éticas que, por lo demás, conlleva semejante conversión: en efecto, «¡todo lo que es técnicamente posible es justificable éticamente?» (Blasco Aznar, 2004: 416). 
rialismo metodológico», cuyo «objetivo principal no consiste en representar, sino en intervenir y operar, producir y transformar»; y agrega acto seguido: "Todo es material" significa, en este caso, que todo es indefinidamente operable y el resultado de operaciones» (2006: 31).

El sujeto de la tecnociencia, este mismo sujeto que ejerce la maestría (trans)formadora de sus manos sobre una materia «indefinidamente operable», no es sino aquel que materializa en última instancia el viejo sueño cartesiano de que los hombres se conviertan en «dueños y poseedores de la naturaleza» (Descartes, 2010: 84). Ahora bien, a la vez que lo lleva más que nunca a vivir y a aprehenderse a sí mismo como un «imperio dentro de un imperio», resulta que la tecnociencia, debido a su planetarización, tiende, para decirlo con la terminología heideggeriana, a brindarle al sujeto una «imagen global del mundo» en virtud de la cual la naturaleza se le aparece en la forma de un inmenso depósito de energía siempre dispuesta a ser explotada, almacenada, distribuida y consumida; y los entes que la pueblan, en la forma de "existencias" o "fondos", en el sentido de stock de un almacén»; vale decir, en «su pura disponibilidad, su puro estar prestos para el uso» (Rodríguez, 2006: 162, 165). Asimismo, no es de extrañar que esta forma que, en la era tecnocientífica, tiene el ente de manifestarse como producto disponible y manipulable también concierna al productor mismo, pues al ser pars naturae, como tiene a bien recalcar Spinoza, se sigue automáticamente del llamamiento a convertirse en dueño y poseedor de la naturaleza el que el hombre se vuelva amo y señor del hombre mismo. El precio de dominar la naturaleza externa es, en efecto, dominar la naturaleza interna. Y así es como, en el marco de una convergencia inaudita entre tecnociencia y capitalismo neoliberal, el hombre se ve empujado a concebirse a sí mismo, al igual que sus elementos constitutivos, en la forma de un material explotable y valorizable, como de ello dan testimonio sintagmas ya banalizados como los de «factor humano», «recurso humano» o «capital humano».

La tecnociencia actual realiza el proyecto moderno: el hombre se convierte en amo y señor de la naturaleza. Pero al mismo tiempo la desestabiliza profundamente, ya que bajo el nombre de la «naturaleza» hay que contar también todos los constituyentes del sujeto humano: su sistema nervioso, su código genético, su computer cortical, sus captadores visuales, auditivos, sus sistemas de comunicación, especialmente los lingüísticos, y sus organizaciones de vida en grupo, etc. (Lyotard, 1986: 32).

Así como es preciso levantar acta del amplio proceso de convergencia que se da entre la tecnociencia y el capitalismo actual - y ello hasta el punto 
de que se habla en ocasiones de tecnocapitalismo-, asimismo nos interesa reparar en la figura cardinal que ha posibilitado y orquestado semejante proceso convergente, a saber: el ingeniero. Él, más que el economista, es quien prolonga el interrogante tecnocientífico « ¿Qué puedo hacer o fabricar?» en el utilitarista « ¿Cómo puedo lograr que todo lo que funciona funcione mejor?» (Comité Invisible, 2015: 132); pregunta cuyo sentido, a su vez, tan solo se puede entender plenamente a la luz del imperativo de producción y reproducción de sobrevalor, al que el ingeniero mismo queda subordinado. Es porque ambiciona dar con «la organización rentable [...] de las técnicas más productivas» por lo que se puede decir del capitalismo (actual) que es «esencialmente tecnológico» (Comité Invisible, 2015: 131). Ahora bien, quien está llamado a llevar semejante operación de apropiación privativa a buen puerto no es sino esta «figura triste y sierva» del ingeniero, ya que él es quien tiene el cometido de seleccionar las técnicas más productivas, así como el de organizarlas materialmente en un sistema tecnológico rentable.

En este sentido se divisa que el «especialista y expropiador jefe de las técnicas» (Comité Invisible, 2015: 131) cumple una función a todas luces central en el ya mencionado proceso de «subsunción real del trabajo en el capital»: la de un engranaje a defecto del cual ni la organización rentable de las técnicas (la tecnología) sería posible, ni lo fabricado (por la tecnociencia) sería comercializable (en el mercado). Piedra angular del tecnocapitalismo, el ingeniero es, pues, quien condena la ciencia y la tecnología a una situación de radical heteronomía al posibilitar el tránsito de una ciencia ya conducida por la tecnología a lo que convendría caracterizar como una tecnología-conducida-por-el-mercado, pues del proceso de convergencia de la tecnociencia hacia el capitalismo (cuyo auténtico nombre es la subsunción) se sigue que el destino último de lo fabricado $-\mathrm{y}$ lo mismo vale decir, más generalmente, de todo lo fabricable- no es sino el de ser mercantilizable. Ahora bien, a tenor de las innovaciones tecnocientíficas y biomédicas -que tienen la capacidad efectiva de convertir lo humano en algo biológicamente manipulable-, así como de la lógica de mercado imperante - que subordina aquellas innovaciones a su afán por transformarlo todo en un bien intercambiable-, podemos vislumbrar hasta qué punto el materialismo metodológico, propio de la tecnociencia, está llamado a desdibujarse ante un «materialismo utilitarista miope» (como diría Jean-Pierre Séris), en virtud del cual «lo humano se ve retrotraído a lo celular; lo celular, a lo maquínico; lo 
maquínico, al producto; y el producto, a la mercancía monetarizable» (citado en Luzi, 2017: 47).

\section{EL MODELO TRANSHUMANISTA DE LA PERFECTIBILIDAD O LA SOCIEDAD OLVIDADA}

Si bien es cierto que, con la tecnociencia, «el homo faber vuelve su arte sobre sí mismo y se dispone a rehacer innovadoramente al inventor y fabricante de todo lo demás» (Jonas, 1995: 49), resta que esta ambición de rehacerse a sí mismo - incluso, de ahora en adelante, a partir de la materialidad biológica del cuerpo propio- cobra unas dimensiones inusitadas a la luz del imperativo de adaptabilidad neoliberal, del que el transhumanismo, con su proyecto de hombre aumentado, constituye ciertamente el prolongamiento último. Lo que aquí se dibuja es, en efecto, un «nuevo horizonte biopolítico del capitalismo» (Le Dévédec, 2018) donde los cuerpos y las subjetividades ya no se entienden en la forma de trabas u obstáculos que sería preciso someter a una estricta disciplina, ${ }^{13}$ sino al contrario, «como unas oportunidades que se trata de optimizar con el propósito de explotarlas mejor» (Le Dévédec, 2018: 126). Como bien queda patente, especialmente a la luz de la convergencia de las NBIC, la optimización de lo humano resulta asimismo mucho más invasiva que el mero disciplinamiento heredado del industrialismo y el maquinismo decimonónicos, pues la cuestión, en pocas palabras, ya no radica tanto en convertir al hombre en un simple «apéndice de la máquina» (como diría Marx), sino más bien, en introducir la máquina en el hombre para alcanzar una suerte de estado simbiótico (el cyborg) en virtud del cual las fronteras que, antaño, separaban lo natural de lo artificial, se difuminan ahora «en beneficio de una mixtura medio-dada, medioconstruida donde, a todos los niveles, los elementos naturales se integran en conjuntos artificiales, y viceversa» (Hottois, 1991: 56).

Así es como la tecnociencia, con el beneplácito del capitalismo neoliberal y de su última punta de lanza ideológica, el transhumanismo, se dispone a someter a aquel ente, cuya naturaleza se pensaba inmutable, a un proceso de engomado radical con vistas a perfeccionar artificialmente aquello que, según deploran los partidarios del human enhancement, es naturalmente im-

\footnotetext{
${ }^{13}$ Como sí fue el caso para el biopoder clásico y la correlativa economía del cuerpo productivo, que dominaron el capitalismo industrial decimonónico y que continuaron ejerciendo cierta influencia hasta bien entrado el régimen de acumulación fordista.
} 
perfecto. Fármacos y otras sustancias psicotrópicas para mejorar la atención, la concentración o la creatividad; implantes cerebrales para optimizar las facultades sensoriales o conectar directamente el cerebro con una interfaz digital; medicina regenerativa para paliar los efectos del envejecimiento o incluso revertirlos; miembros robóticos y otras prótesis para incrementar el rendimiento físico: he aquí algunos ejemplos en los que queda recogida la aspiración transhumanista de valerse del progreso tecnocientífico - al que ve literalmente "como un deus ex machina», es decir, como «el destino humano, el instrumento de su salvación» (Damour, 2017: 58) - con el fin de permitir al hombre trascender su humana condición. Tal y como deja abiertamente constancia de ello uno de sus máximos partidarios, el eje vertebrador del paradigma transhumanista estriba en «[rechazar] la presunción crucial que se halla contenida de forma implícita tanto en la futurología tradicional como en la casi totalidad de los pensamientos políticos» y que sostiene que «la condición humana [sería] "una constante" fundamental» (Bostrom, 2021).

El transhumanismo, lejos de tener un alcance meramente terapéutico, a imagen de la medicina puntera que trata de devolver al sujeto-paciente unas aptitudes naturales disminuidas por una enfermedad o un accidente (como en el caso, por ejemplo, de un trasplante de corazón), se caracteriza al contrario por la ambición de llevar al hombre más allá del límite natural de sus aptitudes. ${ }^{14}$ Razón por la cual no faltan críticos como el biólogo Jacques Testart, padre del primer bebé probeta en Francia, para ver en el human enhancement la nueva cara de la eugenesia positiva y, a buen seguro, la fuente de futuras segregaciones bio-socio-tecnológicas de cuyas consecuencias políticas, simbólicas y, en suma, humanas la distópica Gattaca (Niccol, 1997) ya nos brindaba el oscuro, a la vez que preocupante, retrato. Pero, dejando a un lado todo afán prospectivo, lo que nos interesa subrayar aquí es que la transhumanista, a ojos de sus defensores, es una propuesta cuya pretensión no es, en última instancia, más que la de ser una continuación del proyecto humanista:

El transhumanismo puede ser aprehendido como una extensión del humanismo, del que procede en cierta medida. [...] Así como empleamos medios racionales para mejorar la condición humana y el mundo exterior, asimismo nos es posible utilizar tales medios para perfeccionar nuestro organismo (Bostrom, 2021).

\footnotetext{
${ }^{14}$ Cuando no, lisa y llanamente, por la ambición de «dar muerte a la muerte».
} 
Sin embargo, a pesar de reivindicar semejante filiación, conviene destacar primero que el modelo transhumanista de perfectibilidad humana tiende a obviar la vertiente de mejora social, cultural y política que la concepción humanista, tal y como fue ideada y sistematizada por los filósofos de la Ilustración, traía entonces consigo. ${ }^{15}$ El transhumanismo, por su parte, se ciñe fundamentalmente al proyecto de perfeccionar al individuo, testimoniando así cierta falta de consideración hacia el medio externo, ya sea social, económico, político o ecológico, en el que despliega su existencia y efectúa sus actos. En este sentido, se halla bastante alejado del espíritu progresista de las Luces, que «tiene puesta su esperanza y esfuerzo en la modificación de las condiciones externas de existencia del individuo» y que «no suena más que con mejores medios para dominar las fuerzas naturales o mejores instituciones políticas, jurídicas, administrativas, etc.» (Hottois, 1991: 170). Así pues, frente al progresismo «clásico», que «tiende a mejorar indefinidamente el medio en que el individuo vive» (Hottois, 1991: 170), se dirá más bien del transhumanismo - y ello precisamente porque tiene cierta propensión a privilegiar la optimización individual - que tiende a acarrear en último análisis un «olvido de la sociedad» (Le Dévédec, 2015: 96); olvido que, como comprenderemos, no constituye sino el anverso del «individualismo radical» (Rosanvallon, 1992: 98), propio del período postfordista, que el mismo transhumanismo, especialmente el de corte liberal-libertario, no hace más que extremar. En este sentido, se divisa que el proyecto de human enhancement prolonga esta visión asociológica para la cual «no existe algo así como una sociedad, sino tan solo individuos, hombres y mujeres» (como dijo Margaret Thatcher). Pero individuos a los que pronto se les dará la posibilidad, si así lo desean y se lo pueden costear, de mejorar tecnológicamente sus aptitudes (físicas, psicológicas, sensoriales y emocionales), para así poder convertirse, parafraseando a Rousseau (2007: 69), en «todos perfectos y solitarios»; vale decir, en sujetos monádicos que, al ser radicalmente egocentrados, rehúyen de la alteridad y del cara a cara social.

Además de su insuficiente consideración para con el mundo externo, nos interesa subrayar, en segundo lugar, el auténtico abismo que separa la optimización transhumanista de lo planteado por el modelo de perfectibilidad que nos fue legado por la Ilustración, en general, y por la filosofía rous-

\footnotetext{
${ }^{15}$ Aunque es cierto que el transhumanismo, además de una potente ala liberal-libertaria, consta también de un ala socializante más minoritaria, que se interesa por la forma de volver asequibles las tecnologías de optimización, no solo al individuo, sino a la humanidad en su conjunto.
} 
seauniana, en particular. Si existe un punto común entre ambas empresas de mejora humana, la transhumanista y la humanista, este atañe sin duda alguna a lo que consideran ser lo específico de la condición humana, pues el hombre, al no encontrarse engarzado en una naturaleza o una esencia previamente dada, como sí es el caso del animal, siempre tendría la posibilidad, adosándose en su razón y voluntad, de cambiarse a sí mismo, de devenir otro, a poder ser, para mejor. En otras palabras, lo paradójico de la naturaleza humana radicaría en que acusa una ausencia de naturaleza en virtud de la cual el hombre sería libre de ser lo que hace consigo mismo. Ahora bien, si el modelo transhumanista de mejora humana resulta mucho más invasivo que el humanista, es porque, lejos de limitarse al cultivo de dotes naturales ya dadas ${ }^{16}$ incide al contrario en la necesidad de rehacer artificial e íntegramente aquello que la naturaleza, según considera, no ha hecho más que de forma imperfecta.

Asimismo, el postulado de la perfectibilidad e indeterminación humana constituye ciertamente la piedra angular del argumentario transhumanista: la idea de naturaleza humana queda rechazada por cuanto reconduce una lectura esencialista del hombre que nos impide pensar su modificabilidad. En cambio, reconocer al hombre como ser automoldeador significa admitir que «el mejoramiento es, paradójicamente, la esencia de las criaturas cuya existencia precede a la esencia» (Ogilvy, 2011: 81). Frente a esta lectura bioliberal de lo humano, el discurso bioconservador se caracteriza por presuponer «la existencia de una naturaleza humana intocable, concebida además por algunos de forma esencialista» (Diéguez, 2017: 45). Si bien los bioconservadores reconocen que la educación y la cultura permiten mejorar al hombre, no por ello dejan de insistir en los límites que la naturaleza (humana) impone a dicho mejoramiento, pues «por muy plástico y variable que sea el comportamiento humano, no lo es infinitamente» (Fukuyama, 2002: 14). En este sentido los bioconservadores, especialmente Fukuyama y Kass

\footnotetext{
${ }^{16}$ Lo que requiere paciencia, dedicación y esfuerzo; en suma, una ascesis o Bildung, a defecto de que no puede haber progreso subjetivo. Por ello resulta muy plausible que el transhumano, precisamente porque lo delegará a su aparataje biotecnológico, no sepa nunca qué es el progreso, pues lo que en este caso progresará no será el sujeto, sino el objeto-máquina que este mismo sujeto lleve incorporado. Y ello sin hablar —en clave psicoanalítica - de todo lo que esto podría conllevar en lo que a la hipertrofia del Ello se refiere, pues, si se puede pronosticar que el transhumano presentará un sesgo marcadamente pulsional, es por la sencilla razón de que el precio a pagar por preferir la apropiación inmediata de nuevas aptitudes a costa de su lenta y laboriosa adquisición, como lo exige cualquier proceso autoformativo, no es otro que el de acabar sumido en una profunda inmadurez afectiva. Conque nos podríamos preguntar si el hombre aumentado, lejos del Übermensch nietzscheano, no será en última instancia un hombre disminuido.
} 
(2002), tienen el mérito de «[tomar] en consideración la corporeidad del humano»y, más generalmente, de «[reconocer] la pertenencia del ser humano al mundo viviente» (Le Dévédec, 2017: 53).

No obstante, es preciso señalar el retroceso que supone el bioconservadurismo con respecto a los logros de la modernidad política y democrática. Pues, en última instancia, tanto la «sacralización de la vida» en Kass, como la «esencialización de la naturaleza humana» en Fukuyama desembocan en «posiciones reaccionarias que resultan tan problemáticas como pueden serlo las perspectivas tecnocientíficas defendidas por el transhumanismo» (Le Dévédec, 2017: 50): retorno a una moral tradicional con tintes religiosos en Kass y defensa de un naturalismo desacomplejado en Fukuyama.

Por nuestra parte, creemos en la posibilidad de elaborar una concepción no esencialista de la naturaleza humana desde la que criticar al transhumanismo, sin recaer en la «semántica [bioconservadora] de la persona intangible y sagrada» (Haber, 2005: 237). Para ello, convendría enfocar primero la naturaleza humana como una «generalidad infradeterminada», es decir, como algo que, pese a ser común a los hombres, se actualiza de mil maneras diferentes e insiste a través de sus múltiples determinaciones empírico-históricas sin agotarse jamás en ellas — «una naturaleza humana y mil maneras de ser hombre» (Lordon, 2015: 243). A partir de este esquema de una generalidad infradeterminada que queda implicada en las determinaciones concretas que la expresan, se podría rebatir luego las interpretaciones bioconservadora y transhumanista de una naturaleza humana definida, ora como conjunto fijo y cerrado de notas definitorias, ora como algo infinitamente plástico y moldeable. Finalmente, sería posible realzar cuánto el cuerpo vivido, como lugar de inscripción de la naturaleza humana, se aleja de la «negación [transhumanista] de la carne», pues podría ser que el auténtico mejoramiento no estribase en «conquistar un cuerpo técnicamente superior, sino un cuerpo dotado de una intensidad de vida superlativa» (Sorosina, 2020: 12).

\section{TRAS EL ENROLAMIENTO TOTAL DE LAS SUBJETIVIDADES, LA COLONIZACIÓN INTEGRAL DE LOS CUERPOS}

Basándose en una «antropología de la deficiencia» (Le Dévédec, 2015: 98) - en la que, dicho sea de paso, la denuncia neoliberal de la falta originaria de adaptabilidad podría perfectamente encontrar su fundamento-, el 
transhumanismo tiene a bien retratar al hombre como un «ser biológicamente discapacitado» (Le Dévédec, 2015: 97). En primer lugar, este último sería intelectualmente mediocre, como de ello ya habría dejado constancia la supercomputadora Deep Blue al derrotar al campeón de ajedrez Garry Kaspárov. Luego, adolecería de una constitución física y mental globalmente frágil, tal y como lo atestiguaría su marcada propensión a estar enfermo y a padecer toda clase de trastornos psíquicos. Finalmente, por si no fuera suficiente, gozaría de una vida demasiado breve, pese al considerable - aunque desigual - aumento de la esperanza de vida del que se ha beneficiado la humanidad desde el último siglo. Y todo ello sin mencionar el hecho de que se vería irremediablemente abocado a ser el espectador pasivo de su propio proceso de degeneración continua, cuyos efectos - hasta ahora irremediables - los tratamientos antiedad y la cirugía plástica procuran disimular mal que bien.

Más que de la ideología del progreso, tal y como fue promovida por pensadores como Condorcet, Saint Simon o Comte, el transhumanismo es, en realidad, deudor de lo que podríamos denominar una ideología de la ruptura: insatisfechos con el funcionamiento normal de nuestra especie, cuando no - para decirlo con palabras de Neruda- «cansados de ser hombres», los transhumanistas ambicionan adosarse a las innovaciones tecnocientíficas y biomédicas para preparar — en clave individualista - una salida fuera de la condición humana. Ahora bien, del proyecto de enmendar, en pos de una condición transhumana, todas las deficiencias que se derivan en particular de la materialidad biológica del cuerpo propio (constitución endeble, patologías, envejecimiento, etc.), se sigue irremediablemente un singular acoplamiento: el del ya mencionado individualismo radical con lo que conviene llamar el «culto a la "salud perfecta"» (Lafontaine, 2014: 18). Y es que, bajo el prisma transhumanista, el hombre ya no es solo un capital humano, sino más profundamente, un capital biológico, que, al tener ahora la oportunidad de asomarse por la ventana tecnocientífica de la optimización indefini$\mathrm{da}$, se convierte asimismo en un «cuerpo-mercado» (como dice Lafontaine), en el que cada cual está llamado, según sus preferencias y recursos económicos, a invertir. De lo anterior se puede colegir finalmente que la transhumanista es una "perfectibilidad del cuerpo» donde el mismo, vuelto «por completo objetivado, fragmentado y molecularizado» (Lafontaine, 2014: 18, 29), está presto para ser intervenido (¿invadido?) por todo un aparataje biotecnológico. Y así es como la antropología de la deficiencia, cuyas premisas ya se pueden atisbar en la denuncia neoliberal de la falta de adaptabilidad hu- 
mana, viene a ser completada por una suerte de mística del cuerpo aumentado, que entronca - a la vez que lo prolonga - con el llamamiento postfordista a que cada cual se aprehenda a sí mismo como una unidad de producción cuya competitividad debe ser objeto de un incremento indefinido. ${ }^{17}$

El movimiento por el que el capitalismo postfordista se dispone, según parece, a transitar por la vía del «biocapitalismo» va ciertamente parejo de una ideología doble: la primera presenta el cuerpo como una realidad esencialmente vulnerable y que sufre, como si expresara silenciosamente una demanda infinita de medicación e intervención médica; la segunda celebra por el contrario el fin del cuerpo [tal y como lo conocemos] gracias a los implantes y a las prótesis tecnológicas (Haber y Renault, 2007: 24).

Si el transhumanismo, con su proyecto de intervenir el cuerpo biológico para optimizarlo, se nos aparece, pues, como el codificador ideológico por antonomasia del capitalismo postfordista en su versión biotech, es, para decirlo en pocas palabras, porque encarrila la gubernamentalidad neoliberal hacia la posibilidad - que le brinda ahora la tecnociencia- de devenir carne; esto es, de inscribirse, ya no solo en la interioridad del sujeto, sino directamente en la materialidad biológica misma de su cuerpo. Así es como el proyecto neoliberal de colonización integral de las almas parece estar más que nunca a punto de ser completado por el proyecto transhumanista de colonización integral de los cuerpos.

\section{CONCLUSIÓN}

Bajo el contenido manifiesto del mensaje transhumanista — que espejea una salud perfecta, una eterna juventud y unas aptitudes siempre mejoradas-, despunta pues su contenido latente, a saber: el que se confunde con una suerte de management biológico cuyo cometido estriba en llevar el individuo a interiorizar materialmente la presión exógena, que ejercen sobre él una sociedad y una economía de mercado altamente agonísticas, para así transmutarla en una motivación endógena que lo determine a considerar

\footnotetext{
${ }^{17}$ El hombre transhumano, cuyas piezas constitutivas (implantes, prótesis, estimuladores cerebrales, etc.) no serán sino desechables - y ello en virtud del creciente proceso de obsolescencia programada al que, a buen seguro, dichas piezas estarán sometidas—, se verá asimismo en la obligación de renovarse constantemente en pos de afianzar su competitividad (personal, familiar, laboral, económica, etc.). Ni que decir tiene de la suerte que correrá entonces el hombre ordinario, es decir, aquel que se habrá negado a (o no habrá podido) subirse al tren transhumanista de la revolución biotecnológica...
} 
como legítimo el poder equiparse con artefactos biotecnológicos y afiance en él el deseo de continuar siendo competitivo. En este sentido, no es en absoluto de extrañar que pensadores transhumanistas como Anders Sandberg lleguen incluso a reivindicar el «derecho a la libertad morfológica» (citado en Le Dévédec, 2018: 124), es decir, no solo el derecho a disponer de su cuerpo, sino también el de poder modificarlo a voluntad; reclamo de libertad cuyo auténtico nombre, en última instancia, no es sino la «obediencia feliz» (Lordon, 2010a: 85) al proyecto antropogénico de corte neoliberal, del que el human enhancement no constituye sino la culminación. Pues así como el lento y laborioso proceso de selección sociohistórica habría desembocado, según sostiene Hayek, en la constitución de «órdenes espontáneos» (sociedad y economía de mercado), cuyo cuestionamiento tan solo traería involución socioeconómica y política, ${ }^{18}$ asimismo sería a la tecnociencia, vía la convergencia de las NBIC, a quien correspondería ahora, como defiende el transhumanismo, tomar el relevo de la evolución natural; entiéndase: a quien competería eliminar el azar de la selección darwiniana en pos de la elección racional, para de este modo poder programar y luego dar a luz al hombre nuevo, el único ser capaz de adaptarse adecuadamente a unos órdenes espontáneos altamente competitivos. En efecto, no cabe duda de que el hombre optimizado loado por los transhumanistas designa ante todo «un hombre perfectamente adaptado a las normas de la competencia contemporánea y a los valores centrales de rendimiento, crecimiento, productividad y competitividad ilimitados a los que naturaliza por completo» (Le Dévédec, 2015: 98). Así, aquella nueva humanidad, con la que soñaba Lippmann para su ciudad libre, es ahora el transhumanismo quien, por mediación de la tecnociencia, ambiciona entregársela. Y entregársela en versión aumentada.

\section{BIBLIOGRAFÍA}

Becker, Gary (1983). El capital humano. Madrid: Alianza Editorial. Blasco Aznar, Pedro Luis (2004). Fundamento antropológico de la bioética. Thémata. Revista de Filosofía, 33, 415-421.

Bostrom, Nick (2021). Qu'est-ce que le transhumanisme? Recuperado de: https://iatranshumanisme.com/transhumanisme/quest-ce-que-

\footnotetext{
${ }^{18} \mathrm{Y}$ de la que el colectivismo y el totalitarismo serían el nombre, como bien queda recogido en Camino de servidumbre (Hayek, 2007).
} 
le-transhumanisme-version-3-2/ [Consultado el 3 de febrero de 2021].

Boyer, Robert (1986). La théorie de la régulation: une analyse critique. Paris: La Découverte.

Comité Invisible (2015). A nuestros amigos. Logroño: Pepitas de Calabaza.

Damour, Franck (2017). Le transhumanisme, une idée chrétienne devenue folle? Études, 7-8, 51-62.

Dayan-Herzbrun, Sonia (2005). Un homme nouveau pour un monde nouveau. Tumultes, 25(2), 85-96.

Descartes, René (2010). Discurso del método. Madrid: Espasa Calpe.

Diéguez Lucena, Antonio (2017). Transhumanismo. La búsqueda tecnológica del mejoramiento humano. Barcelona: Herder (1.. edición digital).

EFE (2021, 1 de febrero). La empresa de Musk implanta un chip a un mono para que use videojuego con la mente. Eldiario.es. Recuperado de: https://www.eldiario.es/tecnologia/empresa-muskimplanta-chip-mono-use-videojuego-mente_1_7185257.html [Consultado el 4 de febrero de 2021].

Ellul, Jacques (2008). La technique ou l'enjeu du siécle. Paris: Economica. Foucault, Michel (2007). Nacimiento de la biopolítica. Buenos Aires: Fondo de Cultura Económica.

Fraser, Nancy (2003). ¿De la disciplina a la flexibilización? Releyendo a Foucault bajo la sombra de la globalización. Revista Mexicana de Ciencias Sociales y Politicas, 46, 15-33.

Fukuyama, Francis (2002). Our Posthuman Future. Consequences of the Biotechnology Revolution. New York: Farrar, Straus and Giroux.

Haber, Stéphane (2005). Critique de l'anti-naturalisme. Etudes sur Foucault, Butler et Habermas. Paris: PUF.

Haber, Stéphane y Renault, Emmanuel (2007). Une analyse marxiste des corps. Actuel Marx, 41(1), 14-27.

Hayek, Friedrich (2007). Camino de servidumbre. Madrid: Alianza. 
Hottois, Gilbert (1991). El paradigma bioético. Una ética para la tecnociencia. Barcelona: Anthropos.

Hottois, Gilbert (2006). La technoscience: de l'origine du mot à ses usages actuels. Association de recherche en soins infirmiers, 86(3), 2432.

Jonas, Hans (1995). El principio de responsabilidad. Ensayo de una ética para la civilización tecnológica. Barcelona: Herder.

Kass, Leon (2002). Life, Liberty and the Defense of Dignity. The Challenge for Bioethics. San Francisco: Encounter Books.

Lagasnerie, Geoffroy de (2012). La derniére leçon de Michel Foucault. Sur le néolibéralisme, la théorie et la politique. Paris: Fayard.

Lafontaine, Céline (2014). Le corps-marché. La marchandisation de la vie humaine à l'ére de la bioéconomie. Paris: Éditions du Seuil.

Latour, Bruno (1992). Ciencia en acción. Barcelona: Labor.

Laval, Christian y Dardot, Pierre (2013). La nueva razón del mundo. Barcelona: Gedisa.

Le Dévédec, Nicolas (2015). Retour vers le futur transhumaniste. Esprit, 11, 89-100.

Le Dévédec, Nicolas (2017). Entre la sacralisation de la vie et l'essentialisation de la nature humaine: un examen critique du bioconservatisme. Politique et Sociétés, 36(1), 47-63.

Le Dévédec, Nicolas (2018). Corps et âme: la transhumanisme, nouvel horizon biopolitique du capitalisme? En Le Bot, Florent, Dard, Olivier, Didry, Claude, Dupuy, Camille y Perrin, Cédric (eds.). L'homme-machine II. Du travailleur augmenté à l'homme augmenté (117-136). Paris: L'Harmattan.

Lippmann, Walter (2011). La Cité libre. Paris: Les Belles Lettres. Lordon, Frédéric (2010a). Capitalisme, désir et servitude. Marx et Spinoza. Paris: La Fabrique.

Lordon, Frédéric (2010b). Le totalitarisme, stade ultime du capitalisme? Cités, 41(1), 127-142.

Lordon, Frédéric (2013). La société des affects. Pour un structuralisme des passions. Paris: Le Seuil. 
Lordon, Frédéric (2015). Imperium. Structures et affects des corps politiques. Paris: La Fabrique.

Luzi, Jacques (2017). Le capitalisme transhumaniste et la mort. Écologie \& Politique, 55(2), 33-62.

Lyotard, Jean-François (1986). La posmodernidad explicada a los niños. Barcelona: Gedisa.

Marx, Karl (2008). El capital. Madrid: Siglo XXI, Tomo I / vol. 1.

Niccol, Andrew (1997). Gattaca. CA: Columbia Pictures \& Jersey Films.

Ogilvy, James (2011). Human enhancement and the computer metaphor. Journal of Evolution and Technology, 22(1), 81-96.

Rodríguez, Ramón (2006). Heidegger y la crisis de la época moderna. Madrid: Síntesis.

Rosanvallon, Pierre (1992). La crise de l'État-providence. Paris: Le Seuil.

Rousseau, Jean-Jacques (2007). Contrato social o principios de derecho político. Madrid: Espasa Calpe.

Sorosina, Arnaud (2020). Nietzsche critique du transhumanisme. Fécondité d'un anachronisme philosophique. Revue Médecine et Philosophie, 4, 8-15. doi: http://dx.doi.org/10.51328/102

Spinoza, Baruch (1986). Tratado político. Madrid: Alianza Editorial.

Steger, Manfred y Roy, Ravi (2011). Neoliberalismo. Una breve introducción. Madrid: Alianza.

Stiegler, Barbara (2019). Il faut s'adapter. Sur un nouvel impératif politique. Paris: Gallimard.

Vázquez García, Francisco (2005). «Empresarios de nosotros mismos». Biopolítica, mercado y soberanía en la gubernamentalidad neoliberal. En Vélez, Rafael (ed.). Géneros extremos/extremos genéricos. La política cultural del discurso pornográfico (73-103). Cádiz: Servicio de Publicaciones de la Universidad de Cádiz.

Winner, Langdon (2002). Are humans obsolete? The Hedgehog Review: Critical Reflections on Contemporary Culture, 4(3), 25-44. 